\title{
KONCEPT OZNAKE GEOGRAFSKOG POREKLA HRANE U FUNKCIJI PROMOCIJE KULTURNOG TURIZMA
}

\author{
Nataša Kilibarda, \\ Vule Mizdraković, \\ Ivana Brdar \\ Univerzitet Singidunum, \\ Beograd, Srbija
}

\begin{abstract}
Rezime:
Tradicionalna i autentična hrana nekog podneblja kreira sliku o određenoj destinaciji čineći je na taj način prepoznatljivom u odnosu na druge lokalitete. Koncept oznake geografskog porekla pre svega predstavlja garanciju porekla i kvaliteta hrane koja potiče sa određenog područja, što je današnjem potrošaču veoma važno, a što su potvrdila i istraživanja. Gastronomsku sliku Srbije čine turističke destinacije sa ponudom autentičnih jela, čiji vrhunski kvalitet i jedinstvenost garantuju oznake geografskog porekla. Potencijal gastronomskog turizma u Srbiji postoji. Međutim, neophodno je da se na svim nivoima, od lokalnih zajednica do najviših instanci, uključe i motivišu svi oni koji se bave proizvodnjom hrane i turizmom. Dugoročnom strategijom omogućio bi se razvoj održivog turizma, napredovanje lokalnih zajednica, a samim tim dao bi se doprinos razvoju tržišne ekonomije Srbije.
\end{abstract}

Ključne reči:

hrana, kvalitet, poreklo, tradicija, turizam

\section{UVOD}

Vino, hrana i turizam su proizvodi koji se razlikuju na osnovu svog geografskog porekla. Postoje poznate vrste vina, kao i poznate vrste sireva čiji se kvalitet prepoznaje na osnovu karakteristika geografskog područja sa kojeg potiču. Slično hrani i piću i turizam se promoviše na osnovu znamenitosti koje se nalaze i prepoznaju na određenom lokalitetu, odnosno turističkoj destinaciji. Zato, ne čudi da je veza između vina, hrane i turizma, na regionalnom nivou, odnosno na nivou jedne turističke destinacije, veoma značajna, budući da upravo geografsko poreklo pruža mogućnost brendiranja i promocije destinacije, a kroz to i ekonomski razvoj lokalnih zajednica (Hall, 2003). Mnoge turističke destinacije, prepoznale su značaj i korist veze turizma i hrane, pa su u cilju promocije turizma osmislile da turistima ponude svoje tradicionalne specijalitete i autohtona jela (Kivela \& Crotts, 2005; Hashimoto \& Telfer, 2006; Okumus et al., 2007; McKercher et al., 2008). Hrana, kao svojevrsna i specifična ponuda neke destinacije, vrlo često se predstavlja turistima kroz različite događaje kulturnog tipa. Kao vid kulturnog turizma, gastronomske manifestacije su jedan od načina da se turisti susretnu sa tradicionalnim i specifičnim jelima i upoznaju sa kulturom i istorijom određenog podneblja, budući da je
Correspondence:

Nataša Kilibarda

e-mail:

nkilibarda@singidunum.ac.rs 
poznato da tradicionalne tehnologije i zanati koji se primenjuju u pripremi hrane zapravo oslikavaju istoriju i kulturu jednog naroda. Koncept autentičnosti je veoma važan faktor koji pozitivno utiče na broj posetilaca nekoj turističkoj destinaciji, manifestaciji ili restoranu u njoj (Sims, 2009). Zato su kreiranje i razvoj koncepta autentičnosti posebno važni za unapređenje turizma, naročito u slabije razvijenim krajevima, a jedan od načina da istaknemo svoju kulturu, tradiciju i duh istorije je upravo kroz primenu koncepta autentičnosti na hranu i piće (Banjac et al., 2014).

\section{OZNAKE GEOGRAFSKOG POREKLA HRANE}

Hrana najčešće prezentuje područje sa kojeg potiče i na kojem se proizvodi i na taj način vremenom ona postaje simbol određenog lokaliteta, odnosno oslikava autentičnost neke destinacije. Zbog toga se koncept oznake geografskog porekla najčešće i vezuje za hranu. Samim tim, za proizvode koji imaju oznaku geografskog porekla, može se reći da je ta oznaka simbol njihove različitosti i ona omogućava da se jasno postavi granica između nečeg što je kvalitetno i nečeg što je manje kvalitetno. Budući da je današnji potrošač sve zahtevniji po pitanju vrednosti koju dobija za novac, on postavlja i veće zahteve po pitanju kvaliteta. Sa stanovišta hrane, dakle, on insistira na onoj koja je visokog i ujednačenog kvaliteta. Jedan od aspekata kvaliteta hrane jeste i njeno geografsko poreklo, o kojem potrošači sve više žele da znaju. Proizvođači su, takođe, uvideli značaj ovog aspekta kvaliteta, te se kao posledica zainteresovanosti i potrošača i proizvođača, još osamdesetih godina, razvio koncept oznake geografskog porekla, kao deo celine prava intelektualne svojine (Rilakovic, 2013). U skladu sa tim, Evropska unija je razvila tri različite oznake za kvalitet od kojih su dve usko vezane za geografski element, dok se treća oznaka u većem stepenu odnosi na tradicionalne tehnologije proizvodnje hrane. Ipak, sve tri oznake imaju jedinstveni cilj, a to je očuvanje autentičnosti hrane (Radovanović, 2014). U Republici Srbiji ovu oblast reguliše Zakon o oznakama geografskog porekla (Sl. Glasnik RS 18/2010) koji, za razliku od zakona Evropske unije oznake geografskog porekla, definiše kao pravo kojim se štite dve vrste (kategorije) oznaka kvaliteta: ime porekla i geografske oznake (Radovanović, 2014).

Geografske oznake (eng. Protected Geographical Indication) predstavljaju oznake koje identifikuju (obeležavaju) određenu robu poreklom iz određenog regiona, lokaliteta ili države, a gde se kvalitet, renome ili druge specifične karakteristike robe suštinski mogu pripisati geografskom poreklu (mikro i makro klimatskim uslovima koji su karakteristični za to područje). Proizvodnja i/ili prerada i/ili priprema mora da se odvija na tom ograničenom geografskom području, odnosno, barem jedna od faza proizvodnje se mora odvijati na tom lokalitetu. Ova oznaka predstavlja fleksibilniju kategoriju geografskog porekla.

Ime porekla (eng. Protected Designation of Origin) predstavlja restriktivniju kategoriju geografske oznake i predstavlja naziv određenog regiona, lokaliteta ili mesta (ređe države) kojim se obeležava određeni proizvod koji odatle potiče i čiji su kvalitet i specifične karakteristike isključivo uslovljeni geografskom sredinom, ali uključuju i prirodne i ljudske faktore. Drugim rečima, potrebno je da postoji jasna veza između osobina proizvoda i geografskog porekla (mikro i makro klimatski uslovi karakteristični za to područje), kao i da su autentične osobine tog proizvoda uslovljene veštinama, odnosno znanjima i postupcima (tradicijama) koje poseduju ljudi i koriste ih tokom proizvodnje hrane. Takođe, neophodno je da se sve faze proizvodnje u celini odvijaju na tom geografskom području.

Spomenuli smo da u Evropskoj uniji postoji i treća kategorija oznake geografskog porekla, a to su Garantovano tradicionalni specijaliteti (eng. Traditional Specialty Guaranteed). Ovaj termin odnosi se na poljoprivredne i prehrambene proizvode koji su proizvedeni na tradicionalni način, od tradicionalnih sirovih materijala ili sadrže tradicionalne sastojke, odnosno uspostavljeni su od pojedinaca kroz vremenski period koji nije kraći od 25 generacija. Njihova proizvodnja može biti bilo gde na svetu, ali u skladu sa određenim uslovima. Primer popularnog garantovanog tradicionalnog specijaliteta je vrsta sira mocarela (Mozzarela), koja se može proizvoditi bilo gde u svetu, korišćenjem bilo koje vrste sirovog mleka, ali uz strogo pridržavanje tradicionalne tehnologije (Giovannucci et al., 2009).

Ove oznake ne treba mešati sa oznakom porekla (Indication of Source), kao što je na primer Made in Italy, koja se nalazi na deklaracijama hrane jer one ne ukazuju ni na kakvu vezu između većeg stepena kvaliteta i geografskog porekla. Oznake geografskog porekla su zaštićene oznake i deo su istorijskog, kulturnog, ekonomskog i pravnog sistema, kao jedinstveni izraz lokalnih poljoprivrednih, ekoloških i kulturnih karakteristika i 
predstavljaju prava intelektualne svojine (Đorđević \& Sredojević, 2014). Samim tim možemo reći da oznakama geografskog porekla potvrđujemo da je specifičnost i kvalitet proizvoda nastala u jedinstvenoj kombinaciji lokalnih prirodnih resursa (klime, zemljišta, životinjskih vrsta/rasa ili biljnih sorti) i tradicije, znanja i veština koje se prenose sa generacije na generaciju, a sve to na određenom geografskom području.

Brojne su prednosti hrane sa oznakom geografskog porekla, a samim tim i koristi od nje. Oznaka geografskog porekla garantuje veći kvalitet i autentičnost. Takođe, njima se, pre svega, sprečava obmana kupaca koji kupovinom zaštićenih proizvoda dobijaju zagarantovan kvalitet. Oznaka geografskog porekla daje određenom proizvodu i dodatnu vrednost, a ona, pre svega, proizilazi od svojstava podneblja sa kojeg hrana potiče i na kom se proizvodi i zavisi upravo od kombinacije uslova na određenom geografskom području (vetar, klima, reljef, zemlja, vazduh, voda, ljudski faktor). Proizvođačima hrane ova oznaka predstavlja bitno marketinško sredstvo kojim proizvođači imaju mogućnost da dođu u prednost u samoj trci na tržištu jer imaju mogućnost da svoj proizvod, za koji imaju dokazan kvalitet, istaknu „u moru“ sličnih proizvoda (ali ne i sličnih po kvalitetu). Registrovanjem oznake geografskog porekla proizvod stiče pravnu zaštitu od zloupotrebe imena i falsifikovanja (Rilakovic, 2013). Na taj način se sprečava pokušaj drugih da eksploatišu reputaciju proizvoda označenog geografskog porekla i obmanjivanjem potrošača protivpravno stiču značajna finansijska sredstva.

\section{POLJOPRIVREDNI I PREHRAMBENI PROIZVODI SA OZNAKOM GEOGRAFSKOG POREKLA U SRBIJI}

U svetu postoji preko 10.000 proizvoda koji imaju zaštićeno geografsko poreklo. U svetu oko 90\% proizvoda zaštićenog geografskog porekla potiču iz država članica Organizacije za ekonomsku saradnju i razvoj (eng. Organisation for Economic Co-operation and Development), a svega 10\% proizvoda sa oznakom geografskog porekla potiče iz država u razvoju (Giovannucci et al., 2009). Međutim, bez obzira na ove podatke, interesantno je napomenuti i to da jedni od najprepoznatljivijih proizvoda sa oznakama geografskog porekla zapravo potiču iz država u razvoju, primer toga jesu meksička tekila, kolumbijska kafa, darjeeling čaj sa Himalaja, basmati pirinač iz Indije, itd. Čak šest hiljada proizvoda sa oznakom geografskog porekla potiču iz država članica Evropske unije, a među njima, po broju zaštićenih proizvoda, prednjači Italija, a zatim slede Francuska, Španija, Portugalija i Grčka. Najveći broj zaštićenih proizvoda su poljoprivredni i prehrambeni proizvodi poput mesa, sireva, žitarica, voća, povrća i ulja (Giovannucci et al., 2009).

Oznakama geografskog porekla označavaju se prirodni proizvodi (voda, kamen, itd.), zatim, poljoprivredni (kupus, beli luk, malina, itd.), prehrambeni (sir, kulen, kobasica, itd.), industrijski (pivo i sl.), proizvodi domaće radinosti (ćilim, vez, itd.) i usluge (Čigota program i sl.) vino i druga alkoholna pića. Najveći broj proizvoda obeležen oznakama geografskog porekla su poljoprivredni i prehrambeni proizvodi.

U Srbiji postoji ukupno 59 domaćih oznaka geografskog porekla zaštićenih u Zavodu za intelektualnu svojinu, dakle zaštićenih na nacionalnom nivou. Od tog broja, oznaku geografskog porekla (ime porekla ili geografsku oznaku) imaju 42 poljoprivredna i prehrambena proizvoda, a geografsku oznaku porekla imaju i 9 vrsta vina i 4 vrste prirodnih voda. Četiri oznake geografskog porekla odnose se na različite usluge. Proizvodi od mesa (njih 12) i sirevi (njih 13) su prehrambeni proizvodi koji su najbrojniji kada je u pitanju registrovana i zaštićena oznaka geografskog porekla. Iza njih slede poljoprivredni proizvodi kojih u Srbiji ima ukupno šest (na primer, futoški kupus, ariljska malina i dr.), zatim med (ukupno pet), dve oznake geografskog porekla ribe i ribljih proizvoda, kao i jedna geografska oznaka mesa i jedna geografska oznaka čaja. U odnosu na površinu koju zauzimaju regioni u Srbiji, može se reći da region Vojvodine i region Južne i Istočne Srbije imaju podjednak broj poljoprivrednih i prehrambenih proizvoda zaštićenih oznakom geografskog porekla, Vojvodina 14 proizvoda, a Južna i Istočna Srbija 17. U regionu Centralne i Zapadne Srbije zapaža se da broj proizvoda (prehrambenih i poljoprivrednih) koji nose oznaku zaštićenog geografskog porekla (11 proizvoda) ne oslikavaju stvarne gastronomske karakteristike ovog kraja koje su autentične, jedinstvene i nastale postojanjem kako prirodnih uslova ovog kraja, tako i bogatim kulturnim i istorijskim uticajima.

Oznake geografskog porekla se na međunarodnom nivou registruju putem Lisabonskog aranžmana. Međutim, samo tri proizvoda iz Srbije - leskovački domaći ajvar, homoljski med i fruškogorsko vino „bermet“ imaju međunarodnu oznaku kvaliteta, što im omogućava prodaju na tržištima u više od 25 država širom sveta. Međutim, ovaj sporazum je potpisalo samo 27 država. Kada je u pitanju registracija proizvoda na nivou Evropske unije, Srbija nema registrovan nijedan proizvod zaštićenog geografskog porekla (Samardžić et al., 2013). 
Priznata oznaka geografskog porekla na nivou Evropske unije osigurala bi veću cenu zaštićenog proizvoda, nesmetanu trgovinu i predstavlja bi dobru promociju, kako za proizvođača, tako i za celu državu ili region iz kojeg potiče. Za uspešnu zaštitu geografskog porekla na nivou Evropske unije potrebno je jako udruženje proizvođača, uključivanje svih zainteresovanih strana u proces, posebno onih unutar područja zaštite geografske oznake, kao i dobro osmišljena marketing strategija.

\section{EKONOMSKI ZNAČAJ HRANE SA OZNAKOM GEOGRAFSKOG POREKLA}

Za hranu sa oznakom geografskog porekla može se reći da je marketinško sredstvo koje omogućava bolji plasman proizvoda, višu cenu, veći stepen poverenja kupaca, kao i priliku za kreiranje novog brenda. Kada je reč o ekonomskom značaju proizvoda sa oznakom geografskog porekla, procenjeno je da učestvuju u svetskoj trgovini sa preko 50 milijardi dolara ostvarenih od njihove prodaje (Giovannucci et al., 2009). Takođe, postoje podaci i da je 30\% proizvoda (isključujući vina i žestoka pića) brendiranih na osnovu geografskog porekla izvezeno i to u iznosu od 700 miliona evra u Evropskoj uniji (Đorđević \& Sredojević, 2014). Značajna tržišta proizvoda sa oznakama geografskog porekla su pre svega Sjedinjene Američke Države i države članice Evropske unije. Iako nema zvaničnih podataka, smatra se da u Francuskoj prihodi od trgovine hranom sa geografskom oznakom porekla učestvuju sa oko 10\% ukupne zarade od prodaje hrane, dok u Italiji ova oblast privrede angažuje oko 300.000 ljudi, a u Španiji, ukupna zarada od proizvoda zaštićenog geografskog porekla procenjena je na oko 3,5 milijarde evra (Vats, 2016).

Značaj hrane sa oznakom geografskog porekla sagledan je kroz više pozitivnih uticaja na ekonomske aspekte (Simović, 2015). Pre svega, utvrđeno je da proizvodi sa oznakama geografskog porekla imaju više cene (za u proseku od $20 \%$ do $50 \%$ ). Viša cena ovih proizvoda potiče od troškova koji se javljaju prilikom postupaka registracije i sertifikacije. Budući da je koncept oznake geografskog porekla takav da štiti proizvođača od nelojalne konkurencije, jasno je i da oni koji su uložili u sam proces zaštite oznake porekla svog proizvoda mogu da očekuju i veću zaradu koja im se kroz plasman ovih proizvoda i vraća. Sa druge strane, ovakavim načinom poslovanja, kada proizvođači sagledaju sve koristi i upuste se u proces registracije, smanjuje se broj onih koji posluju u okvirima „sive ekonomije“, jer ih proces registracije i sertifikacije preusmerava u legalne tokove, što nesumnjivo ima značaja za budžet države. Olakšan je izvoz zaštićenih proizvoda na svetsko tržište jer su oznake prepoznatljive svuda u svetu. Zatim, dugoročno gledajući, zapaža se i pozitivni uticaj i na obim proizvodnje, jer zbog porasta tražnje i širenja tržišta, proizvodnja određenog proizvoda se povećava, kako bi se izašlo u susret zahtevima koje postavlja tržište. Zaštitom proizvoda geografskim oznakama porekla izbegava se efekat nestabilnosti cena na tržištu jer su primarni proizvođači, zahvaljujući minimalnoj dogovorenoj ceni u okviru svojih udruženja, zaštićeni od ovih fluktuacija. Zatim, uticaj na ekonomiju se ogleda i u činjenici da određeni proizvodi koji nisu zaštićeni oznakama geografskog porekla, a potiču sa istog geografskog područja na kojem se taj proizvod iste kategorije, ali zaštićenog geografskog porekla proizvodi, povećava svoju cenu na osnovu reputacije imena onog proizvoda koji ima oznaku (Vandecandelaere et al., 2018). Sve to skupa ima uticaj da se u određenom regionu pospešuje proizvodnja, a što sigurno ima uticaja i na lokalni razvoj nerazvijenih područja. Na ovaj način, na određenoj destinaciji otvaraju se nova radna mesta, povećava se broj zaposlenih, a ujedno sve to predstavlja i potencijal šansu za razvoj turizma.

Proizvod sa oznakom geografskog porekla potrošači doživljavaju kao proizvod koji je kvalitetniji u odnosu na druge. Ipak, uvek se postavlja pitanje, budući da su proizvodi sa oznakama geografskog porekla po pravilu i skuplji, da li su potrošači spremi da odvoje veći iznos novca za kupovinu ovih proizvoda. Istraživanjem koje je sprovedeno na 20.000 stanovnika Evropske unije utvrđeno je da za njih 37\% glavni motiv za kupovinu ove hrane bio da je to proizvod garantovanog i poznatog porekla, za njih 35\% motiv za kupovinu je bio taj što će za izdvojeni novac dobiti očekivan kvalitet, zatim za $31 \%$ stanovnika EU glavni razlog opredeljenosti za ovu vrstu proizvoda bilo je mesto porekla i tehnologija proizvodnje, dok je za 16\% njih razlog bio tradicionalni način proizvodnje. Ovim ispitivanjem utvrđeno je i da je od ukupnog broja ispitanika, preciznije za $51 \%$ njih, potpuno prihvatljivo da izdvoji od 10 do $20 \%$ više novca za proizvod sa geografskom oznakom porekla u odnosu na sličan proizvod koji ne poseduje oznaku porekla (Giovannucci et al, 2009). Scuras i Vakrou (2002) su dokazali da su neiskusni kupci vina spremni da plate duplo veću cenu za bocu vina ukoliko je istaknuta informacija o geografskom poreklu. Slično je dokazano i kada je u pitanju prodaja ulja, gde su potrošači pokazali spremnost da izdvoje više novca 
za ulje sa geografskom oznakom nego bez nje (Menapace et al., 2011). Ipak, uvek se postavlja i pitanje kupovne moći stanovništva, pre svega u nerazvijenim i državama u razvoju, odnosno da li i pored postojanja želje i motiva za potrošnjom ovih proizvoda, postoji i kupovna moć stanovništva koja bi im ove proizvode učinila dostupnim.

\section{OZNAKA GEOGRAFSKOG POREKLA I EFEKAT NA TURIZAM}

Hrana je ekonomski i kulturni resurs koja nudi vrlo opipljive koristi kada se koristi u cilju promocije turizma (Buiatti, 2011). Treba biti svestan da svaka vrsta hrane, čak i ona najuobičajenija i najjednostavnija zapravo oslikava istoriju i kulturu jednog naroda. Istoriju nekog regiona, zatim, istoriju identiteta jednog naroda, porodičnu istoriju, ali i istoriju religije - jednom rečju, hrana može da prepriča istoriju kulture jednog naroda koji živi u određenom regionu. Lokalna hrana neke turističke destinacije, kada je autentična, jedinstvena i zaštićena, kreira posebnu sliku te destinacije, čineći je prepoznatljivom u odnosu na druge. Ukusi tradicionalne hrane daju poseban doprinos jedinstvenosti doživljenih ukusa i povećavaju stepen zadovoljstva i opšteg utiska kod turista (Zaman \& Kayserili, 2015). Prethodno navedeno je veoma značajno sa aspekta turizma, imajući u vidu i podatak da prethodno turisti na hranu i piće troše i do jedne trećine svog budžeta na putovanju (Hall \& Sharples, 2003). Prepoznatljiv i geografskom oznakom zaštićen proizvod u značajnoj meri može postati važan promoter turističke destinacije sa koje potiče. Pre svega, on štiti od zaborava tradicionalne tehnologije i običaje čija je promocija jedan od načina podsticanja turizma. U ovom slučaju i određena destinacija i zaštićen proizvod postaju neraskidiva celina, te prepoznatljivost i uspeh proizvoda sa geografskom oznakom, u marketinškom smislu, povećava atraktivnost neke turističke destinacije. Tome u prilog govori i činjenica da se danas pojam tradicionalne hrane u Evropi usko vezuje za koncept tipične hrane određenog regiona. Samim tim, dolazi se do zaključka da je koncept regionalne hrane značajno povezan sa konceptom geografskog označavanja hrane. Istraživanja su pokazala da je učesnicima ankete veoma važno da dobiju informaciju o tome iz kog regiona potiče hrana koju konzumiraju, da im je država porekla veoma bitna karakteristika, kao i da im ukus hrane zavisi od regiona u kom se proizvodi i iz kog potiče (Stojanović \& Ognjanov, 2012).

Objašnjenja za sve veći broj turista koji pokazuju interesovanje za turističke destinacije koje nude tradicionalna jela visokog kvaliteta i poznatog porekla ima nekoliko. Turisti su, naravno, pre svega potrošači (konzumenti hrane), a iz perspektive potrošača, oni su sve više zabrinuti kada je reč o bezbednosti i kvalitetu hrane koju konzumiraju (naročito posle bolesti novijeg datuma kao što su bolest „ludih krava“, ptičiji grip itd.) (Buiatti, 2011). Sa druge strane sve je veći broj turista koji pokazuju veliko interesovanje za prirodnu i organsku hranu, te sumnjajući u kvalitet onoga što se nudi u supermarketima, idealnim odmorom za dušu i telo smatraju odlazak u turističke destinacije, daleko od buke i gužve, gde će na raspolaganju imati hranu poznatog i proverenog kvaliteta. Jasno je da geografsko označavanje tradicionalnih, inače, već prepoznatljivih proizvoda po kvalitetu, otvara prostor za promociju turizma na određenoj destinaciji.

Države koje žele da povećaju svoje učešće u svetskom turizmu, daju veliki značaj razvoju i promociji gastronomskog turizma, ističući pri tome jedinstvenost i autentičnost lokalnih specijaliteta karakterističnih za određene destinacije, koji zaštićeni, garantuju poreklo, viši i ujednačen kvalitet koji se ne menja tokom vremena i koje pri ponovnoj poseti određenoj destinaciji, turisti mogu ponovo da očekuju (Yıkmıs \& Ünal, 2016). Glavni cilj gastronomskog turizma, turizma koji u cilju promocije određene turističke destinacije u prvi plan ističe bogatu, autentičnu i kvalitetnu gastronomsku ponudu je čvrsto usmeren na razvoj održivog turizma čiji je osnovni cilj očuvanje prirode i kulture, povećanje zadovoljstva turista i optimizacija dugoročnog ekonomskog razvoja (Buiatti, 2011). Iz tog razloga je posebno važno da strategija za razvoj proizvoda sa oznakom geografskog porekla na nivou lokalnih udruženja bude potpomognuta strategijom koja uključuje i druge lokalne aktere i javnu podršku (Živkov et al., 2014).

\section{ZAKLJUČAK}

Soulfood Serbia naziv je marketinške kampanje Turističke organizacije Srbije za 2012. godinu koja je za glavnu temu imala promociju autentičnih gastronomskih proizvoda Srbije, sa posebnim akcentom na one koji imaju ili treba da dobiju oznaku zaštićenog geografskog porekla. Činjenica da je promotivni spot koji je 
kreiran u okviru ove kampanje dobio više priznanja i nagrada na međunarodnom nivou, govore u prilog tome da je gastronomska ponuda Srbije prepoznata na gastronomskoj mapi sveta. Gastronomsku sliku Srbije čine turističke destinacije sa ponudom autentičnih jela čiji vrhunski kvalitet i jedinstvenost garantuju oznake geografskog porekla. Potencijal gastronomskog turizma u Srbiji postoji i što je najvažnije prepoznat je. Međutim, neophodno je da taj potencijal, kako na nivou lokalnih zajednica, zatim preko svih onih koji se bave turizmom, ali i na nivou državnih organa, bude podržan jasnom strategijom koja bi omogućila razvoj turizma, ali i drugih privrednih delatnosti koje bi uticale na razvoj tržišne ekonomije Srbije.

\section{LITERATURA}

Banjac, M., Živković, M., Cvetković, B., \& Babić, J. (2014). Offer Of Authentic Cold Appetizers in the Hospitality and Turist Facilities. Researches Reviews of the Department of Geography, Tourism and Hotel Management, 43(1), 87-96.

Buiatti, S. (2011). Food and tourism: the role of the "Slow Food" association. In: K. L. Sidali, A. Spiller, \& B. Schulze (Eds.), Food, Agri-Culture and Tourism. Linking local gastronomy and rural tourism: interdisciplinary perspectives (pp. 92-101). Berlin: Springer.

Đorđević, T., \& Sredojević, Z. (2014). Značaj brendiranja proizvoda putem zaštićenog geografskog porekla. U: S. Ognjanov, \& G. Mitić (Urednici), Marketing prehrambenih proizvoda (pp. 132-151). Beograd: Dosije studio.

Giovannucci, D., Josling, T., William, K. A., O'Connor, B., \& Yeung, M. T. (2009). Guide to Geographical Indications - Linking Products and Their Origins. Geneva: International Trade Centre.

Hall, C.M, \& Sharples, L. (2003). The consumption of experiences or the experience of consumption? An introduction to the tourism of taste. In C. Hall, L. Sharples, \& R. Mitchell, Food Tourism Around the World: development, management and markets (pp. 1-13). Oxford: Butterworth-Heinemann.

Hall, C. M. (2003). Food tourism around the world: development, management and markets. Oxford: Butterworth-Heinemann.

Hashimoto, A., \& Telfer, D. J. (2006). Selling Canadian culinary tourism: branding the global and the regional product. Tourism Geographies, 8(1), 31-55.

Kivela, J., \& Crotts, J. C. (2005). Gastronomy tourism: a meaningful travel market segment. Journal of Culinary Science \& Technology, 4(2/3), 39-55.

McKercher, B., Okumus, F., \& Okumus, B. (2008). Food tourism as a viable market segment: it's all how you cook the numbers! Journal of Travel \& Tourism Marketing, 25(2), 137-148.

Menapace, L, Colson, G, Grebitus, C. i Facendola, M. (2011) Consumers' preferences for geographical origin labels: Evidence from the Canadian Olive Oil Market. European Review of Agricultural Economics, 38(2), 193-212.

Okumus, B., Okumus, F., \& McKercher, B. (2007). Incorporating local and international cuisines in the marketing of tourism destinations: the cases of Hong Kong and Turkey. Tourism Management, 28(1), 253-261.

Radovanović, N. (2014). Nacionalna i međunarodna zaštita poljoprivrednih i prehrambenih proizvoda putem oznaka geografskog porekla- slučaj Srbije. U S. Ognjanov, \& G. Mitić (Urednici), Marketing prehrambenih proizvoda (str. 115-126). Beograd: Dosije studio.

Rilakovic, I. (2013). Oznake geografskog porekla. Pravno-ekonomski pogledi, IV(3), 50-62.

Samardžić, S., Ivanković, M., Bajramović, S., Ostojić, A., Sarić, Z., \& Popović-Vranješ, A. (2013). Tipični proizvodi kao predmet intelektualnog vlasništva kroz istorijski i geografski pregled. Agroznanje, 14(3), 397-409.

Simović, K. (2015). Agro-prehrambene šeme kvaliteta na nivou EU i potencijalne koristi zaštite srpskih proizvoda u kontekstu pregovora sa EU - Predlog praktične politike. Beograd: Centar za evropske politike.

Sims, R. (2009). Food, place and authenticity: local food and the sustainable tourism experience. Journal of Sustainable Tourism, 17(3), 321-336.

Skuras, D. and Vakrou, A. (2002) Consumers' willingness to pay for origin labelled wine: A Greek Case Study. British Food Journal, 104(11), 898-912.

Službeni glasnik Republike Srbije 18/2010. Zakon o oznakama geografskog porekla. Beograd: JP „Službeni glasnik“

Stojanović, Ž., \& Ognjanov, G. (2012). Strategic orientation of rural developmetn in Serbia - production and marketing of traditional food. Economic Themes, 50(1), 19-32. 
Vandecandelaere, E., Teyssier, C., Barjolle, D., Jeanneaux, J., Fournier, S., \& Beucherie, O. (2018). Strengthening sustainable foodcsystems through geographical indications - An analysis of economic impacts. Rome: Food and Agriculture Organization of the United Nations (FAO).

Vats, N. K. (2016). Geographical Indication - The Factors of Rural Development and Strengthening Economy. Journal of Intellectual Proprety Rights, 21, 347-354.

Yıkmıs, S., \& Ünal, A. (2016). The importance of geographical indication in gastronomy tourism: Turkey. International Journal of Agricultural and Life Sciences- IJALS, 2(4), 73-79.

Zaman, S., \& Kayserili, A. (2015). The Role of Geographical Signs in Gastronomy Tourism: A Case Study of Erzurum Cag Kebab. International Journal of Academic Research in Environment and Geography, 2(1), 40-45.

Živkov, G., Tar, D., Dulić Marković, I., Marković, A., Teofilović, N., \& Raketić, B. (2014). Dodati vrednost proizvodima. Agrikultura. Preuzeto Avgust 31, 2018 sa http://www.eastagri.org/meetings/docs/meeting96/ Background\%20Paper\%20SRB.pdf

\title{
THE CONCEPT OF THE GEOGRAPHICAL ORIGIN OF FOOD IN PROMOTING CULTURE TOURISM
}

\begin{abstract}
:
Traditional and authentic foods, create an image of a particular destination, making it so recognizable in relation to other sites. The concept of a geographical indication is primarily a guarantee of origin and quality of food originating from a particular area, which is very important to today's consumers. The gastronomic image of Serbia consists of tourist destinations with authentic dishes, whose top quality and uniqueness guarantee geographical indications. Therefore, the potential of gastronomic tourism in Serbia exists. However, it is necessary to include and motivate all those involved in food production and tourism at all levels, from local communities to the highest instances. A long-term strategy would enable the growth of sustainable tourism, the development of local communities, and thus contribute to Serbian market economy.
\end{abstract}

Keywords :

food, quality, origin, tradition, tourism 